\title{
Desempenho de ovinos em capim-tanzânia sob lotação rotativa com quatro proporções de suplementação concentrada
}

[Performance of sheep raised on Tanzania grass under intermittent stocking with four proportions of concentrate supplementation]

\author{
R.C.F.F. Pompeu ${ }^{1}$, M.J.D. Cândido 2 , J.N.M. Neiva ${ }^{3}$, M.C.P. Rogério ${ }^{4}$, M.A.B. Cavalcante ${ }^{5}$, R.G. Silva ${ }^{3}$ \\ ${ }^{1}$ Aluno de pós-graduação \\ Programa Integrado UFC/UFPB/UFRPE - Fortaleza, CE \\ ${ }^{2}$ Universidade Federal do Ceará - Fortaleza, CE \\ ${ }^{3}$ Universidade Federal do Tocantins - Araguaína, TO \\ ${ }^{4}$ Universidade Estadual do Vale do Acaraú - Sobral, CE \\ ${ }^{5}$ Agência Estadual de Defesa Agropecuária - Fortaleza, CE
}

\begin{abstract}
RESUMO
Avaliou-se o desempenho de ovinos em capim-tanzânia sob lotação rotativa com quatro proporções de suplementação concentrada $0 \%, 0,6 \%, 1,2 \%$ e $1,8 \%$ do peso vivo (PV), e oito repetições, em delineamento inteiramente ao acaso, com período de ocupação de três dias e descanso de 21 dias. Foram avaliados o ganho médio diário (GMD), o ganho de peso total (GPT), o número de dias para alcançar $12 \mathrm{~kg}$ (D12), a taxa de lotação em ovinos/ha (TLO) e em UA/ha (TLUA), o rendimento de peso vivo (RPV) e a conversão alimentar do concentrado (CAC). Observou-se efeito quadrático da proporção de suplementação sobre o GMD que foi estimado em 65,87 e $113,15 \mathrm{~g} /$ dia para os animais não suplementados e suplementados com 1,8\% do PV. O suplemento também teve efeito quadrático sobre o GPT. O D12 estimado para os ovinos não suplementados foi de 204 dias, reduzindo-se para 113 dias para os animais suplementados com 1,8\% do PV. Quanto à TLO e TLUA, observou-se efeito quadrático da proporção de suplementação. Observou-se efeito linear negativo da proporção de suplementação sobre RPV. A CAC foi melhor entre os animais suplementados com $0,6 \%$ do PV. A utilização da suplementação até $1,2 \%$ PV melhorou o desempenho dos ovinos em pastejo.
\end{abstract}

Palavras-chave: ovino, rendimento, Panicum maximum, taxa de lotação, terminação

\begin{abstract}
This study evaluated the performance of sheep raised on Tanzania grass under intermittent stocking with four supplementation proportions $0 ; 0.6 ; 1.2$, and $1.8 \%$ of live weight $(L W)$ and eight replicates, in a completely randomized design with tree grazing periods, and 21 rest periods. The average daily gain $(G M D)$, the total weight gain (GPT), the days to reach $12 \mathrm{~kg}(D 12)$, the stocking rate (sheep/ha - TLO and animal unit/ha - TLUA), the live weight yield (RPV), and the concentrate: gain ratio (CAC) was evaluated. It was observed a square effect of supplementation proportions on GMD, estimated in 65.87 and $113.15 \mathrm{~g} /$ day for male sheep that was not supplemented and received $1.8 \% \mathrm{LW}$ supplement. It was observed a square effect of supplementation level on GPT. The D12 to 0\% LW level was estimated in 204 days, decreasing to 113 days when the sheep received $1.8 \% \mathrm{LW}$ supplement. It was observed square effects of supplementation proportions on TLO and TLUA. It was observed a negative linear effect of supplementation proportions on RPV. The CAC presented the best response for sheep that received $0.6 \%$ $L W$ supplementation proportion. It can be concluded that sheep supplementation until $1.2 \% \mathrm{LW}$ level provided improvement on performance of grazing sheep.
\end{abstract}

Keywords: sheep, yield, Panicum maximum, stocking rate, finishing

Recebido em 31 de agosto de 2008

Aceito em 10 de setembro de 2009

E-mail: roberto_agronomia@yahoo.com.br 


\section{INTRODUÇÃO}

A exploração de ovinos na região Nordeste do Brasil apresenta baixos índices de produtividade em decorrência das flutuações na disponibilidade e qualidade das pastagens, devido principalmente à má distribuição de chuvas ao longo do ano, resultando em elevada idade dos animais ao abate.

A suplementação em pasto é uma alternativa eficiente para o aumento da produção animal, pois, segundo Hodgson (1990), na maioria das situações, a forragem disponível na pastagem não contém todos os nutrientes essenciais, na proporção adequada, de forma a atender integralmente às exigências dos animais em pastejo. Portanto, a condição básica para se promover a suplementação é que haja elevada disponibilidade de massa de forragem na pastagem, mesmo sendo de baixa qualidade. Nesse último, o consumo, a digestão, a absorção e o metabolismo estão sendo adversamente influenciados pela deficiência nutricional.

A suplementação permite regular a oferta de alimento e aumentar o rendimento animal, pois o aumento na quantidade de suplemento resulta em menor contribuição da pastagem, pois, dependendo do tipo de suplemento, há elevação da capacidade de suporte do pasto (Euclides, 2002). Dessa forma, observa-se a grande contribuição da suplementação no aumento do ganho de peso do animal por área, não comprometendo a estrutura do pasto.

O objetivo deste trabalho foi avaliar o desempenho de ovinos em pastejo de capimtanzânia sob lotação rotativa, com proporções crescentes de suplementação concentrada.

\section{MATERIAL E MÉTODOS}

O experimento foi realizado no campo avançado do Núcleo de Ensino e Estudos em Forragicultura, utilizando ovinos em pastejo de Panicum maximum cv. Tanzânia sob lotação rotativa, com proporções crescentes de suplementação concentrada. A área está localizada em Pentecoste/CE, situada nas latitudes $3^{\circ} 40^{\prime}$ a $3^{\circ} 51^{\prime} 18^{\prime \prime}$ sul e longitudes $39^{\circ} 10^{\prime} 19^{\prime \prime}$ e $39^{\circ} 18^{\prime} 13^{\prime \prime}$ oeste, em uma região cujo clima, segundo a classificação de Köeppen, é do tipo BSw'h', semiárido quente, com precipitação média anual de $806,5 \mathrm{~mm}$, distribuída no período de janeiro a abril. Os dados de temperatura média, umidade relativa do ar, radiação e insolação do local no período experimental (setembro a dezembro de 2004) foram de $27,1^{\circ} \mathrm{C}$, $65,5 \%, 27,3 \mathrm{MJ} / \mathrm{m}^{2}$ dia e $9,3 \mathrm{~h}$, respectivamente.

Foram utilizados 32 ovinos sem padrão racial definido (SPRD), oito animais por tratamento, com idades variadas, (até 1 ano e meio) e com peso médio inicial de $20 \mathrm{~kg}$. Outros ovinos foram sorteados e utilizados como animais de equilíbrio.

Foram avaliadas quatro proporções de suplementação concentrada em ovinos pastejando Panicum maximum cv. Tanzânia sob lotação rotativa. As proporções de suplementação (tratamento) foram: 0,0;0,6;1,2 e $1,8 \%$ do peso vivo (PV) dos ovinos, por dia. A área dos piquetes foi suficiente de modo a garantir uma oferta de forragem de 7,2\% PV, o dobro do consumo máximo esperado de matéria seca, considerando uma taxa de crescimento cultural (TCC) de 140kg MS/ha x dia, conforme preconizado por Silva (2004).

O método de pastejo adotado foi o de lotação rotativa, com taxa de lotação variável Put and Take, descrito por Mott e Lucas (1952). A área total, de $1.472 \mathrm{~m}^{2}$, foi dividida em oito piquetes de $183,6 \mathrm{~m}^{2}$. Cada piquete foi provido de comedouros, bebedouros e sombrites. O período de descanso de 21 dias correspondeu ao tempo necessário para a expansão de duas novas folhas por perfilho, conforme estimado por Silva (2004), e o período de pastejo foi de três dias. Os ovinos de equilíbrio foram utilizados, quando necessário, para garantir o rebaixamento da vegetação para uma altura residual de $28 \mathrm{~cm}$, correspondente a um índice de área foliar de 1,0 (Silva, 2004), ao final do terceiro dia de pastejo.

Todos os ovinos receberam somente sal mineral à vontade. Os suplementados receberam concentrado uma vez ao dia, sempre às $13 \mathrm{~h}$, considerando a capacidade de consumo máximo diário de MS de 3,6\% do peso vivo para ovinos em terminação. Os dados referentes à composição centesimal do suplemento concentrado encontram-se na Tab. 1. O suplemento concentrado foi formulado com base no NRC (Nutrient..., 1985), considerando-se $20 \mathrm{~kg}$ de peso vivo, ganho de $250 \mathrm{~g}$ diário e crescimento moderado. 
Tabela 1. Composição da ração concentrada de cordeiros em terminação, na base de matéria natural

\begin{tabular}{|c|c|}
\hline Ingrediente & $\%$ \\
\hline Milho grão & 87,5 \\
\hline Soja Farelo & 5,0 \\
\hline Ureia & 3,0 \\
\hline Calcário & 1,7 \\
\hline Suplemento mineral ${ }^{1}$ & 1,5 \\
\hline Fosfato bicálcico & 0,9 \\
\hline Sal comum & 0,4 \\
\hline
\end{tabular}

${ }^{1}$ Composição por quilo: fosfato, $65 \mathrm{~g}$; cálcio, $160 \mathrm{~g}$; enxofre, $15 \mathrm{~g}$; magnésio, 6,5g; sódio, $150 \mathrm{~g}$; cobalto, $0,125 \mathrm{~g}$; zinco, $4,5 \mathrm{~g}$; ferro, $1,7 \mathrm{~g}$; manganês, $4,5 \mathrm{~g}$; iodo, 0,06g; selênio, $0,03 \mathrm{~g}$; flúor, $0,95 \mathrm{~g}$.

Para efeito de caracterização do alimento fornecido, foram coletadas amostras do concentrado e do capim-tanzânia para realização de análises químico-bromatológicas. Nas amostras da fração foliar pré-seca, determinaram-se os teores de matéria seca (MS), matéria orgânica $(\mathrm{MO})$, proteína bruta $(\mathrm{PB})$, fibra em detergente neutro (FDN), fibra em detergente ácido (FDA), extrato etéreo (EE) e resíduo mineral (RM) conforme técnicas descritas em Silva e Queiroz (2002). Os teores de hemiceluloses (HCEL) foram determinados segundo Silva e Queiroz (2002), os carboidratos totais (CHOT) conforme Sniffen et al. (1992) e os de nutrientes digestíveis totais do concentrado segundo o NRC (Nutrient..., 2001). A composição químico-bromatológica da fração folha do capim-tanzânia e do suplemento concentrado é apresentada na Tab. 2.

Avaliaram-se: ganho médio diário (GMD), ganho de peso total (GPT), número de dias para um ovino ganhar $12 \mathrm{~kg}$ (D12), taxa de lotação, em ovinos/ha (TLO) e em unidades-animal/ha (TLUA), o rendimento de peso vivo médio anual (RPV) e a conversão alimentar do concentrado (CAC). A pesagem dos animais foi realizada a cada 12 dias.

Tabela 2. Composição química da fração folha do capim-tanzânia e do suplemento concentrado

\begin{tabular}{lcc}
\multicolumn{1}{c}{ Variável (\%) } & Folha & Suplemento concentrado \\
\hline Matéria seca & 22,1 & 83,3 \\
Matéria orgânica & 78,4 & 75,4 \\
Proteína bruta & 10,1 & 20,2 \\
Fibra em detergente neutro & 71,3 & 39,1 \\
Fibra em detergente ácido & 43,0 & 3,2 \\
Hemicelulose & 28,3 & 35,9 \\
Extrato etéreo & 4,1 & 3,0 \\
Residuo mineral & 13,2 & 7,9 \\
Carboidratos totais & 72,6 & 68,9 \\
Nutrientes digestíveis totais & - & $80,0^{1}$
\end{tabular}

${ }^{\mathrm{T}}$ Valor estimado conforme dados do NRC (Nutrient..., 2001).

Para o cálculo da TLO, foram registrados o número de animais de prova e de equilíbrio presentes em cada piquete a cada dia, dividindo pelo número de dias do ciclo de pastejo. A taxa de lotação (UA) foi calculada multiplicando a equivalência em unidade animal de um ovino com PV médio de cada tratamento pela TLO. A CAC foi obtida dividindo o consumo médio diário de concentrado de cada tratamento pelo GMD advindo da suplementação em cada tratamento.

Com base nas estimativas de ganho médio diário e da taxa de lotação média de cada sistema rotativo, estimou-se o RPV para cada nível de suplementação.
Utilizaram-se análises de variância e de regressão, tendo o peso inicial como covariável (24kg), já que esses animais tiveram ganhos compensatórios antes de iniciar a pesquisa, durante o período de preparação da área para a alocação dos tratamentos. A escolha dos modelos baseou-se na significância dos coeficientes linear e quadrático, utilizando-se o teste $\mathrm{t}$, a $10 \%$ de probabilidade. Para comparar o efeito dos tratamentos, foi utilizado o teste Tukey, a 5\% de probabilidade. Como ferramenta de auxílio às análises estatísticas, utilizou-se o procedimento GLM, do programa estatístico SAS/1999. 


\section{RESULTADOS E DISCUSSÃO}

O GMD, o GPT, o D12, a TLO, a TLUA, o RPV e a CAC estão apresentados na Tab. 3.

O ganho dos animais suplementados com 1,2\% do $\mathrm{PV}$, de $119 \mathrm{~g} /$ dia não diferiu $(\mathrm{P}>0,05)$ do ganho dos suplementados com $1,8 \%$ do $\mathrm{PV}$ $(111 \mathrm{~g} / \mathrm{dia})$, porém foi mais elevado $(\mathrm{P}<0,05)$ do que os dos demais tratamentos (Tab. 3), e não houve diferença no GMD entre os animais não suplementados e suplementados com $0,6 \%$ do PV. Apesar de o volumoso ter apresentado alto teor de FDN e FDA (Tab. 2), o suplemento fornecido com $20 \%$ de PB até $1,2 \%$ do PV pode ter promovido melhoria na digestibilidade da fibra, aumentando a taxa de passagem ruminal (Faria e Huber, 1984) e, consequentemente, maior consumo da forragem, caracterizando efeito aditivo. Ademais, é possível que a sincronização entre os níveis de proteína e de energia (concentrado com $80 \%$ de NDT, Tab. 2) no rúmen tenha propiciado condições adequadas para a fermentação microbiana na proporção de $1,2 \%$ de suplementação, promovendo melhores condições de digestão e de aproveitamento do alimento.

Na suplementação de 1,8\% PV, o excesso de proteína e energia na ração, especialmente a primeira, associado ao manejo intensivo do pasto (adubação nitrogenada de $600 \mathrm{~kg} / \mathrm{ha} / \mathrm{ano}$ ) e ao curto período de descanso (21d) pode ter causado "consumo de luxo" de nutrientes, especialmente nitrogênio não proteico (NNP), acarretando desequilíbrio energia-proteína na dieta $\mathrm{e}$ causando gasto de energia para eliminar o excesso de amônia no rúmen, além da perda de alimento nas fezes, verificada pela quantidade de grânulos de milho não digeridos na excreta.

Tabela 3. Ganho médio diário (GMD), ganho de peso total (GPT), número de dias para os animais ganharem $12 \mathrm{~kg}$ (D12), taxa de lotação (TLO) e (TLUA), rendimento de peso vivo (RPV) e conversão alimentar do concentrado (CAC) de ovinos terminados em pastagens de capim-tanzânia segundo os tratamentos

\begin{tabular}{|c|c|c|c|c|c|c|}
\hline \multirow{2}{*}{ Variável } & \multicolumn{4}{|c|}{ Suplementação \% do PV } & \multirow{2}{*}{$\begin{array}{l}\text { CV } \\
(\%) \\
\end{array}$} & \multirow{2}{*}{ Equação } \\
\hline & 0,0 & 0,6 & 1,2 & 1,8 & & \\
\hline GMD (g/dia) & $70,3 \mathrm{c}$ & $81,5 \mathrm{bc}$ & $119 \mathrm{a}$ & $111 \mathrm{ab}$ & 26,77 & $\mathrm{Y}=129,1+49,6 \mathrm{x}-13,0 \mathrm{x}^{2}-2,62 \mathrm{Pi} ; \mathrm{R}^{2}=0,41$ \\
\hline GPT (kg) & $6,3 b$ & $7,83 \mathrm{~b}$ & $11,5 \mathrm{a}$ & $11,5 \mathrm{a}$ & 25,40 & $Y=12,0+4,18 x-0,68 x^{2}-0,23 P i ; R^{2}=0,48$ \\
\hline D12 (dias) & $205 b$ & $158 \mathrm{ab}$ & $106 \mathrm{a}$ & $116 \mathrm{a}$ & 36,74 & $Y=135-113 x+34,8 x^{2}+2,87 P i ; R^{2}=0,37$ \\
\hline TLO (ovinos/ha) & $61 b$ & $67 \mathrm{ab}$ & $65 b$ & $73 a$ & 9.51 & $Y=93,0-3,35 x+4,29 x^{2}-1,21 P i ; R^{2}=0,33$ \\
\hline TLUA (UA/ha) & $7,5 b$ & $7,76 b$ & $7,64 b$ & $9,06 \mathrm{a}$ & 9,64 & $Y=8,39-0,82 x+0,86 x^{2}-0,03 P i ; R^{2}=0,38$ \\
\hline $\begin{array}{c}\text { RPV } \\
\text { (kg PV/ha } \mathrm{x} \text { ano) }\end{array}$ & $1483 b$ & $1993 b$ & $2832 \mathrm{a}$ & $3292 \mathrm{a}$ & 24,93 & $\begin{array}{l}Y=3691+958 x-89,2 P i \\
R^{2}=0,63\end{array}$ \\
\hline $\begin{array}{c}\text { CAC } \\
\text { (kg conc. cons/kg } \\
\text { PV ganho) }\end{array}$ & - & $2,5 b$ & $3,52 b$ & $5,81 \mathrm{a}$ & 36,33 & $Y=-4,47+3,50 x+0,19 P i ; r^{2}=0,81$ \\
\hline
\end{tabular}

Médias na mesma linha seguidas de letras iguais não diferem entre si ( $\mathrm{P}>0.05)$, pelo teste Tukey.

Houve efeito quadrático $(\mathrm{P}<0,10)$ da proporção de suplementação sobre o GMD dos animais, estimando-se 66,2 e $113 \mathrm{~g} /$ dia para os animais não suplementados e para aqueles com suplementação de $1,8 \%$ do PV, respectivamente. Isto demonstra o possível efeito positivo da suplementação de até $1,2 \%$ do PV (Tab. 3). A falta de ajuste dos dados contribuiu para o baixo coeficiente de determinação $\left(\mathrm{R}^{2}=0,41\right)$ da equação, em virtude de fatores ligados à raça e ao manejo do pasto. Como os ovinos eram do tipo SPRD, alguns animais eram mais predispostos à infestação por helmintos, tendo, portanto diferentes desempenhos individuais dentro do mesmo tratamento. Adicione-se a isso o fato de os anti-helmínticos usados no início do experimento não terem apresentado eficácia, uma vez que os animais foram oriundos de várias 
fazendas comerciais, dificultando a busca de um anti-helmíntico eficiente, pois não se sabia exatamente qual princípio ativo os animais vinham recebendo anteriormente. Além disso, algumas adubações efetuadas demasiadamente próximo do momento de entrada dos animais em alguns piquetes até metade do período experimental em função de problemas com excesso de água dentro da pastagem em alguns momentos devido ao arrombamento de canais de irrigação adjacentes à área experimental comprometendo o calendário das adubações. Essas ocorrências podem ter contribuído para um excesso de nitrogênio não-proteico na dieta, em consequência da associação de um consumo de luxo de nitrogênio pelo pasto nos últimos dias pré-pastejo, com a presença de $3 \%$ de ureia no suplemento (Tab. 1).

Os dados observados foram inferiores aos de Oliveira et al. (2004) e de Silva (2004), com GMD de 131 e $114 \mathrm{~g} /$ ovino/dia, respectivamente, ao trabalharem com capim-tanzânia. No primeiro caso, a diferença pode estar relacionada ao fato de esses autores terem usado $1,0 \%$ de PV de suplementação para ovinos Santa Inês, sendo esses inteiros e com taxa de lotação mais baixa $(3,0 \mathrm{UA} / \mathrm{ha})$ que a desta pesquisa. No segundo, os animais utilizados pesavam, no início da pesquisa, $20 \mathrm{~kg}$, eram inteiros e tinham idade de seis a oito meses, contra os $24 \mathrm{~kg}$ e a idade acima de um ano no presente trabalho. A partir da equação obtida, estimou-se um GMD de $76,7 \mathrm{~g} /$ ovino/dia para animais não suplementados pesando $20 \mathrm{~kg}$. À medida que a idade aumenta e/ou que o peso vivo se eleva, os incrementos são decrescentes, assim como a conversão alimentar. Ademais, Silva (2004) manteve um índice de área foliar residual (IAF) de 1,0, enquanto no presente experimento o IAF residual no pasto dos animais não suplementados foi de 2,07 (dados não apresentados). Dessa forma, plantas manejadas sob pastejo mais leve podem apresentar pior qualidade nutricional, em virtude de apresentarem menor relação material vivo/material morto (Parsons et al., 1983) e folha/colmo (Santos et al., 2001).

Quanto ao GPT dos animais (Tab. 3), observaram-se variações entre 6,30 a $11,5 \mathrm{kgPV}$ nas proporções de inclusão de concentrado de 0,0 a $1,8 \%$ do PV. Não foi observada diferença $(\mathrm{P}>0,05)$ entre os tratamentos de 0,0 e $0,6 \%$ do $\mathrm{PV}$, mas estes foram menores que os valores observados com os tratamentos 1,2 e $1,8 \%$ do $\mathrm{PV}(\mathrm{P}<0,05)$.

Foi observado efeito quadrático da proporção de suplementação sobre o GPT, estimado em 6,48 e $11,8 \mathrm{~kg}$ do PV para os animais não suplementados e que receberam $1,8 \%$ do PV de concentrado.

Os animais que receberam suplementação de $1,8 \%$ do PV apresentaram ganhos de 5,2kg mais altos que os não suplementados. Medeiros et al. (2004), ao trabalharem com ovinos da raça Morada Nova, castrados, com peso vivo inicial de $19 \mathrm{~kg}$, em confinamento e alimentados com $60 \%$ de concentrado na dieta total, relataram GPT de 11,4kg, porém, com 75 dias em confinamento. Os resultados foram semelhantes aos obtidos com a suplementação de $1,8 \%$ do PV deste trabalho. Maiores GMD e GPT têm efeito de fundamental importância no processo produtivo, permitindo que os animais sejam comercializados para o abate mais precocemente.

Quanto ao D12 (Tab. 3), a suplementação com $1,2 \%$ do PV resultou em menor número de dias para atingir $12 \mathrm{~kg}$, e não diferiu $(\mathrm{P}>0,05)$ das suplementações com $0,6 \%$ e $1,8 \%$ do $\mathrm{PV}$, porém foi menor $(\mathrm{P}>0,05)$ em relação aos animais não suplementados. Em média, os animais entram na fase de terminação com aproximadamente $20 \mathrm{~kg}$ de peso vivo e são comercializados quando apresentam entre 30 e $32 \mathrm{~kg}$. Portanto, quanto menor o tempo de ocupação dos animais no pasto até atingir o peso de abate, maior será a rotatividade do sistema e, consequentemente, maior será o número de lotes terminados por ano e a lucratividade do empreendimento.

As proporções crescentes de suplementação resultaram em efeito quadrático $(\mathrm{P}<0,10)$ sobre o D12, estimado em 204 e 113 dias para os animais não suplementados e suplementados com $1,8 \%$ do PV, respectivamente, e mínimo de 112 dias, com 1,6\% de suplementação. Quando se considerou o peso vivo inicial de $20 \mathrm{~kg}$, estimaram-se D12 de 192 e de 102 dias para a suplementação de $0,0 \%$ e $1,8 \%$ do PV, respectivamente. Portanto, se durante todo o ano os piquetes fossem utilizados sem suplementação, seria possível terminar 1,9 lotes de ovinos (365 dias/192 dias). Se suplementados na proporção de $1,8 \%$ do PV poder-se-ia 
terminar 3,6 lotes (365 dias/102 dias), considerando peso vivo inicial de $20 \mathrm{~kg}$.

O menor valor de D12 estimado para ovinos terminados a partir de $20 \mathrm{~kg}$ PV, 102 dias, é mais alto que o tempo de engorda máximo para ovinos confinados, determinado por Vidal et al. (2004) como sendo de 70 dias. $O$ fato é que a terminação de animais em pasto propicia menor desempenho que o de animais confinados, porém, não há na literatura registro de tempo máximo de terminação em pasto que propicie uma eficiência econômica.

Quanto à TLO (Tab. 3), não se observou diferença $(\mathrm{P}>0,05)$ entre os tratamentos com 0,0 ; 0,6 e $1,2 \%$ do PV com média igual a 64 ovinos por hectare. Entretanto, os tratamentos com 0,0 (61 ovinos/ha) e 1,2\% do PV (65 ovinos/ha) resultaram em menores TLO que a suplementação de 1,8\% do PV.

Houve efeito quadrático $(\mathrm{P}<0,10)$ da proporção de suplementação sobre a TLO, com estimativa mínima de 63 ovinos/ha, com 0,39\% de suplementação. Estimou-se uma TLO para 0,0 e $1,8 \%$ de suplementação de 64 e 72 ovinos/ha, respectivamente. A falta de ajuste dos dados contribuiu para o baixo coeficiente de determinação $\left(\mathrm{R}^{2}=0,33\right)$ da equação, em virtude de fatores ligados principalmente aos animais utilizados, como já comentado anteriormente.

A TLO média observada neste estudo foi mais baixa que a citada por Silva (2004), ao trabalhar com ovinos SPRD inteiros, com PV inicial de $20 \mathrm{~kg}$, sob períodos de descanso de 1,5; 2,5 e 3,5 folhas/perfilhos, com TLO média de $69 ; 74$ e 84 ovinos/ha, respectivamente. Neste trabalho, a menor taxa de lotação em relação a citada por Silva (2004) deveu-se, principalmente, ao maior peso vivo inicial dos ovinos neste estudo $(24 \mathrm{~kg})$, acarretando oferta de forragem similar, porém com menor número de ovinos.

A taxa de lotação em unidades animal por hectare (TLUA) (Tab. 3) teve comportamento semelhante à TLO, isto é, as suplementações de 0,$0 ; 0,6$ e $1,2 \%$ do $\mathrm{PV}$ não diferiram entre si $(\mathrm{P}>0,05)$, com média igual a $7,63 \mathrm{UA} / \mathrm{ha}$, e foram mais baixas que a taxa da suplementação de $1,8 \%$ do PV.
Verficou-se efeito quadrático $(\mathrm{P}<0,10)$ da proporção crescente de suplementação sobre a TLUA, com estimativa de 7,67 e 8,98UA/ha com animais recebendo 0,0 e 1,8\% de suplementação, respectivamente, com um mínimo estimado de $7,47 \mathrm{UA} /$ ha com $0,48 \%$ de suplementação. Este fato é de extrema importância, pois em regiões como o Semiárido Brasileiro, o aumento da taxa de lotação em áreas mais tecnificadas diminui a pressão de pastejo sobre as áreas de pastagens naturais, que apresentam maior fragilidade $\mathrm{e}$ susceptibilidade à degradação.

Além disso, o suplemento utilizado permitiu o aumento da taxa de lotação na pastagem a partir de $1,2 \%$ de suplementação, sem reduzir o GMD, aumentando o ganho por área, sugerindo um efeito substitutivo. Assim, é possível que a maior TLO e TLUA dos animais suplementados com 1,8\% do PV deva-se ao aumento do nível de concentrado com alta densidade energética $(87,5 \%$ de milho - Tab. 1) na dieta total, favorecendo o desenvolvimento da microbiota ruminal amilolítica. Esse possível aumento dos microrganismos amilolíticos acarretaria redução do $\mathrm{pH}$ ruminal, inibindo a atividade da microbiota celulolítica, bastante sensível à queda do $\mathrm{pH}$, acarretando decréscimos no consumo de forragem (Ferrell, 1988; Van Soest, 1994) e aumentando a taxa de lotação pelo efeito substitutivo. Porém, deve-se atentar quanto à economicidade do sistema, pois, apesar do maior ganho por animal e por área no nível de suplementação de $1,8 \% \mathrm{PV}$, tal resposta pode não compensar a elevação no custo com a alimentação concentrada.

Não foram observadas diferenças $(\mathrm{P}>0,05)$ de rendimento de peso vivo (RPV) entre os tratamentos de 0,0 e $0,6 \%$ do PV (Tab. 3), que foram inferiores $(\mathrm{P}<0,05)$ aos encontrados nas proporções de suplementação de 1,2 e $1,8 \%$ do $\mathrm{PV}$, porém estes últimos não diferiram $(\mathrm{P}>0,05)$ entre si.

As proporções crescentes de suplementação resultaram em efeito linear $(\mathrm{P}<0,10)$ sobre o RPV, estimados em 1537; 2113; 2687 e $3262 \mathrm{~kg}$ $\mathrm{PV} /$ ha/ano para os tratamentos 0,$0 ; 0,6 ; 1,2 \mathrm{e}$ $1,8 \%$ do $\mathrm{PV}$, equivalendo a produções diárias de 4,$21 ; \quad 5,79 ; \quad 7,36$ e 8,94kg PV/ha, respectivamente. Para cada $1 \%$ de inclusão de concentrado na dieta, houve elevações de $958 \mathrm{~kg}$ PV sobre o RPV. Quando se estimou o RPV nos 
níveis de suplementação de 0,0 e $1,8 \%$ do PV com o peso vivo inicial de $20 \mathrm{~kg}$, a produtividade foi de 1907 e de $3631 \mathrm{~kg}$ PV/ha/ano, respectivamente. $\mathrm{O}$ valor estimado com os animais não suplementados (1907kg PV/ha/ano) está dentro do intervalo estabelecido por Corsi e Santos (1995) para as metas de exploração intensiva de pastos, os quais sugeriram produtividade entre 1600 e $2000 \mathrm{~kg} \mathrm{PV} / \mathrm{ha} / \mathrm{ano}$, na estação chuvosa.

Corrêa (2000), ao trabalhar com novilhos em pastejo sob lotação rotativa em manejo intensivo (adubação equivalente a $1500 \mathrm{~kg} / \mathrm{ha} / \mathrm{ano}$ na fórmula 20-05-20) com capim-tanzânia, com taxa de lotação de 5,8UA/ha, relatou uma produtividade de $803 \mathrm{~kg} \mathrm{PV} / \mathrm{ha} / \mathrm{ano}$, durante o período das águas. Euclides et al. (1999), ao utilizarem novilhos em capim-tanzânia, com lotação rotativa em sistema intensivo (adubação) e taxa de lotação de 3,2UA/ha no período das águas, obtiveram produtividade de $820 \mathrm{~kg}$ $\mathrm{PV} / \mathrm{ha} / \mathrm{ano}$. Observa-se que os valores aqui obtidos para animais não suplementados $(1537 \mathrm{~kg}$ $\mathrm{PV} / \mathrm{ha} /$ ano) são mais altos que os relatados pelos referidos autores, porém mais baixos que os citados por Silva (2004), que trabalhou com ovinos SPRD, inteiros, e com peso vivo inicial de $20 \mathrm{~kg}$ no Semiárido Brasileiro, em manejo intensivo de capim-tanzânia, com período de descanso equivalente a 1,81 folhas por perfilhos, o qual relatou produtividade de $2975 \mathrm{~kg}$ $\mathrm{PV} / \mathrm{ha} / \mathrm{ano}$.

Dessa forma, observa-se o grande potencial de produção de ovinos em pastagens irrigadas manejadas intensivamente em condições do Semiárido Brasileiro, devido à maior incidência total de radiação solar ao longo do ano, havendo maior potencial de conversão de energia luminosa em energia química (tecidos vegetais), associadas às práticas de manejo, em produto animal.

Quanto à CAC (Tab. 3), não foram observadas diferenças $(\mathrm{P}>0,05)$ entre os tratamentos de $0,6 \mathrm{e}$ $1,2 \%$ do PV, contudo os animais que receberam $1,8 \%$ de suplemento foram menos eficientes quanto à CAC.

Observou-se efeito linear $(\mathrm{P}<0,10)$ da proporção de inclusão de concentrado sobre a CAC, estimado em 2,07; 4,02 e 5,97kg concentrado consumido/kg PV para os tratamentos de 0,$6 ; 1,2$ e $1,8 \%$ PV. Para cada $1 \%$ de suplementação com concentrado, observou-se acréscimo de $3,5 \mathrm{~kg}$ de concentrado para se obter $1 \mathrm{~kg}$ de PV ganho.

Essa redução na conversão alimentar do concentrado com a elevação nos níveis de suplementação pode ser explicada por se tratar de uma pesquisa com suplementação em pastejo, havendo um nível 0,0\% de suplementação. Dessa forma, é possível que uma interação positiva entre suplemento e forragem tenha favorecido o crescimento microbiano, permitindo elevada conversão no nível de suplementação de $0,6 \%$, efeito que se diluiu nos níveis maiores de suplementação (1,2 e 1,8\%), possivelmente em decorrência do menor consumo de forragem pelos ovinos nesses dois últimos tratamentos. Os dados de comportamento corroboram com essa assertiva (dados não apresentados), pois o tempo de pastejo dos ovinos suplementados com 1,2 e $1,8 \%$ do peso vivo foi inferior aos dos demais tratamentos, indicando menor pressão de pastejo sobre a gramínea nos referidos tratamentos. Dessa forma, fica demonstrado que, para as condições de pastagens irrigadas, suplementações com altos níveis de concentrado tendem a diminuir a eficiência de conversão alimentar.

\section{CONCLUSÕES}

O máximo desempenho individual dos ovinos foi obtido a partir da suplementação de 1,2\% do peso vivo, e a máxima produtividade por área foi obtida com suplemententenção de $1,8 \%$ do peso vivo.

\section{REFERÊNCIAS BIBLIOGRÁFICAS}

CORRÊA, L.A. Pastejo rotacionado para produção de bovinos de corte. In: SIMPÓSIO DE FORRAGICULTURA E PASTAGENS, 2000, Lavras, MG. Anais... Lavras, MG: UFLA, 2000. p.149-178.

CORSI, M.; SANTOS, P.M. Potencial de produção do Panicum maximum. In: SIMPÓSIO SOBRE MANEJO DE PASTAGEM: O capimcolonião, 12, 1995, Piracicaba, SP. Anais... Piracicaba, SP: FEALQ, 1995. p.275-304.

FARIA, V.P.; HUBER, J.T. Effect of dietaryprotein and energy-levels on rumen fermentation in Holsteins-Steers. J. Anim. Sci., v.58, p.452$459,1984$. 
EUCLIDES, V.P.B. Estratégias de suplementação em pasto: uma visão crítica. In: SIMPÓSIO SOBRE MANEJO ESTRATÉGICO DA PASTAGEM, 2002, Viçosa, MG. Anais... Viçosa, MG: UFV, 2002. p.437-469.

EUCLIDES, V.P.B.; MACEDO, M.C.M.; OLIVEIRA, M.P. Avaliação de cultivares de Panicum maximum em pastejo. In: REUNIÃO ANUAL DA SOCIEDADE BRASILEIRA DE ZOOTECNIA, 36, 1999, Porto Alegre, RS. Anais... São Paulo: SBZ, 1999. CD-ROM.

FERRELL, C.L. Energy metabolism. In: CHURCH, D.C. (Ed.). The ruminant animal: digestive physiology and nutrition. Englewood Cliffs, NJ: Prentice Hall, 1988. p.250-268.

HODGSON. J. Grazing management: science into practice. Harlow: Longman, 1990. 203p.

MEDEIROS, G.R.; CARVALHO, F.F.R.; FERREIRA, M.A. et al. Níveis de concentrado sobre o desempenho de ovinos Morada Nova em confinamento. In: SIMPÓSIO SOBRE A PRODUÇÃO ANIMAL E A SEGURANÇA ALIMENTAR/ REUNIÃO DA SOCIEDADE BRASILEIRA DE ZOOTECNIA, 41, 2004, Campo Grande, MS. Anais... Campo Grande, MS: SBZ. 2004. CD-ROM.

MOTT, G.O.; LUCAS, H.L. The design, conduct and interpretation of grazing trials on cultivated and improved pastures. In: INTERNATIONAL GRASSLAND CONGRESS, 6, 1952, Pasadena. Proceedings... Pasadena, CA: IGC, 1952. p.1380-1385.

NUTRIENT requirements of dairy cattle. Washington, DC: National Academy Press, 2001. 381p.

NUTRIENT requirements of sheep. Washington, DC: National Academy Press, 1985. 99p.

OLIVEIRA, M.E.; ARAÚJO, D.L.C.; LOPES, J.B. et al. Terminação de ovinos da raça Santa
Inês em pastagem cultivada com uso de suplementação concentrada. In: SIMPÓSIO SOBRE A PRODUÇÃO ANIMAL E A SEGURANÇA ALIMENTAR/REUNIÃO DA SOCIEDADE BRASILEIRA DE ZOOTECNIA, 41, 2004, Campo Grande, MS. Anais... Campo Grande, MS: SBZ, 2004. CD-ROM.

PARSONS, A.J.; LEAFE, E.L.; COLLETT, B. et al. The physiology of grass production under grazing. II. Photosynthesis crop growth and animal intake of continuously-grazed swards. $J$. Appl. Ecol., v.20, p.127-139, 1983.

SANTOS, P.M.; BALSALOBRE, M.A.A.; CORSI, M. Participação de gerações de perfilhos na produção do capim Tanzânia. In: REUNIÃO ANUAL DA SOCIEDADE BRASILEIRA DE ZOOTECNIA, 38, 2001, Piracicaba, SP. Anais... Piracicaba, SP: SBZ, 2001. p.123-124.

SILVA, D.J.; QUEIROZ, A.C. Análise de alimentos: métodos químicos e biológicos. Viçosa, MG: UFV, 2002. 235p.

SILVA, R.G. Morfofisiologia do dossel e desempenho produtivo de ovinos em Panicum maximum (Jacq.) cv. Tanzânia sob três períodos de descanso. 2004. 114f. Dissertação (Mestrado em Zootecnia) - Universidade Federal do Ceará, Fortaleza, CE.

SNIFFEN, C.J.; O'CONNOR, J.D.; VAN SOEST, P.J. et al. A net carbohydrate and protein system for an evaluating cattle diets: II. Carbohydrate and protein availability. J. Dairy Sci., v.70, p.3562-3577, 1992.

VAN SOEST, P.J. Nutritional ecology of the ruminant. Ithaca, NY: Cornell University, 1994. $476 \mathrm{p}$.

VIDAL, M.F.; SILVA, L.A.C.; SOUSA NETO, J. et al. Análise econômica de confinamento de ovinos: o uso da ureia em substituição à cama de frango e a dietas a base de milho e soja. Ciênc. Rural, v.34, p.493-498, 2004. 